\title{
PENGARUH PERCEIVED USEFULNESS, PERCEIVED EASE OF USE DAN TRUST TERHADAP MINAT KONSUMEN DALAM PENGGUNAAN ULANG GO-PAY DI KOTA JAKARTA
}

\author{
Eko Sandy \\ Program Studi Magister Manajemen Universitas Tarumanagara \\ eko.117182022@stu.untar.ac.id \\ Carunia Mulya Firdausy \\ Program Studi Magister Manajemen Universitas Tarumanagara
}

Masuk : 18-05-2020, revisi : 24-06-2020 diterima untuk diterbitkan : 24-06-2020

\begin{abstract}
The number of E-Wallet users in Indonesia keep increasing every year since it's first launching. Several E-Wallet brands compete to be the best E-Wallet in Indonesia. One of them is Go-Pay. This research aims to find out the effect of perceived usefulness, perceived ease of use, and trust on intention to reuse of Go-Pay in Jakarta. A descriptive quantitative research was conducted by analysing data collected from online questionaire survey of 105 respondents. The method to analyse the data is by using multiple linear regression. The result showed that, perceived usefulness did not affect the reuse intention of Go-Pay customers significantly. Whilst perceived ease of use and trust did affect the reuse intention of Go-Pay customers significantly. Trust value has the strongest relationship toward reuse intention of Go-Pay customers. Therefore, Go-Pay company needs to maintain customers trust and also increase or retain Go-Pay application ease of use in doing payment.
\end{abstract}

Keywords : Perceived Usefulness, Perceived Ease of Use, Trust, Intention to Reuse

Abstrak : Jumlah transaksi dan pengguna $E$-Wallet terus bertambah setiap tahunnya sejak pertama kali diluncurkan. Beberapa perusahaan $E$-Wallet saling bersaing untuk menjadi $E$ Wallet terbaik di Indonesia, salah satu perusahaan E-Wallet adalah Go-Pay. Penelitian ini memiliki tujuan untuk mencari pengaruh perceived usefulness, perceived ease of use, dan trust terhadap intention to reuse Go-Pay di Jakarta. Penelitian deskriptif kuantitatif dipilih dan dilakukan terhadap 105 data responden terpilih. Teknik Analisa regresi linear berganda dipilih dan diolah menggunakan perangkat lunak SPSS 24. Hasil menunjukkan bahwa perceived usefulness tidak memiliki pengaruh yang signifikan terhadap intention to reuse konsumen GoPay, namun perceived ease of use dan trust berpengaruh secara signifikan terhadap intention to reuse konsumen Go-Pay. Trust mendapatkan nilai signifikansi yang lebih tinggi terhadap intention to reuse konsumen Go-Pay. Sebagai kesimpulan, hasil penelitian dapat memberikan saran kepada perusahaan Go-Pay untuk mempertahankan kepercayaan konsumen serta meningkatkan atau mempertahankan kemudahan dalam melakukan transaksi menggunakan Go-Pay.

Kata Kunci : Perceived Usefulness, Perceived Ease of Use, Trust, Intention to Reuse

\section{PENDAHULUAN}

Dalam keseharian masyarakat, tentunya akan berinteraksi dan salah satunya yaitu melakukan transaksi (Shidiq \& Warnilah, 2019). Dalam bertransaksi, dibutuhkan alat tukar yang disepakati bersama yaitu uang. Uang sebagai alat pembayaran ini berevolusi dengan cepat dimana awalnya berbentuk koin atau kertas hingga muncul beberapa jenis pembayaran seperti giro, cheque, kartu debit dan kartu kredit (Bagla \& Sancheti, 2018).

Di era tekonologi seperti sekarang ini salah satu jenis pembayaran yang berkembang yakni dengan menggunakan dompet digital atau yang lebih dikenal sebagai $E$-Wallet. Dompet 
digital merupakan dompet yang tidak memiliki bentuk fisik yang dapat diakses melalui perangkat elektronik seperti smartphone maupun komputer serta dapat digunakan untuk bertransaksi (Bagla \& Sancheti, 2018). Sikri, Dalal, Singh, \& Le (2019) menjelaskan dompet digital sebagai mobile technology yang dapat digunakan layaknya seperti dompet pada umumnya serta memberikan kemudahan bagi penggunanya dalam bertransaksi. Dompet digital merupakan inovasi teknologi dengan berbagai fitur untuk memberikan kepraktisan bagi penggunanya (Singh, Srivastava, \& Sinha, 2017). Dalam hal ini, dompet digital menawarkan kecepatan dan kemudahan dalam bertransaksi.

Salah satu contoh perusahaan E-Wallet terbesar di Indonesia adalah Go-Pay. Berdasarkan kutipan berita (Idris, M., 24 Januari 2019), tercatat sebesar 79 persen masyarakat di Indonesia sudah menggunakan Go-Pay pada tahun 2018 dan Go-Pay sejak 2017 secara 3 tahun berturut-turut menjadi dompet digital dengan jumlah transaksi terbesar di Indonesia.

Namun dengan semakin bertambahnya jumlah perusahaan E-Wallet dengan keunggulan masing-masing memunculkan persaingan yang semakin ketat. Hal ini tentunya membuat perusahaan Go-Pay harus mengetahui hal yang dicari konsumen agar mau terus menggunakan Go-Pay. Berdasarkan uraian dan fenomena diatas, penelitian ini bertujuan untuk menganalisis pengaruh perceived usefulness, perceived ease of use, dan trust terhadap intention to reuse konsumen Go-Pay di kota Jakarta.

\section{TELAAH KEPUSTAKAAN}

Dalam mengukur penerimaan sebuah sistem, ada beberapa model yang dapat digunakan. Salah satunya adalah Technology Acceptance Model. Davis (1989) mengembangkan TAM dari model Theory of Reasoned Action (TRA) yang sebelumnya diteliti dan ditulis oleh Ajzen \& Fishbein (1975) dan diharapkan dari penelitian tersebut dapat menemukan dan memvalidasi variabel baru yang dapat digunakan untuk menjadi variabel hipotesa dalam penelitian berbasis komputer. TAM dilakukan pengujian dengan menggunakan 2 variabel pengukuran: Perceived Usefulness dan Perceived Ease of Use. Dalam penelitian tersebut, didapat hasil positif dimana kedua variabel ditemukan memiliki nilai dan pengaruh yang positif antara variabel Perceived Usefulness dan Perceived Ease of Use terhadap perilaku pengguna komputer.

Perceived Userfulness dijelaskan sebagai kepercayaan yang diberikan pengguna sistem kepada sebuah sistem untuk meningkatkan efektivitas atau mengurangi usaha yang keluarkan dalam menyelesaikan pekerjaan mereka. Menurut Davis (1989), Perceived Userfulness memiliki keterkaitan dengan niat orang dalam menggunakan sebuah sistem. Dalam penelitiannya disebutkan bahwa orang akan cenderung menggunakan sistem jika mereka mempercayai bahwa sebuah sistem dianggap dan dipercaya dapat meningkatkan performa dalam menyelesaikan tugas dan tanggung jawab dari penggunanya.

Sedangkan Perceived Ease of Use merupakan sebuah tingkatan dimana seseorang mempercayai bahwa dalam menggunakan sebuah sistem atau pelayanan dapat terbebas dari upaya penggunaan yang besar. Orang cenderung akan menggunakan sebuah teknologi jika teknologi tersebut mudah digunakan. Davis (1989) berteori, Perceived Ease of Use merupakan kondisi dimana pengguna menyadari sebuah sistem mudah untuk digunakan dan tidak memerlukan usaha yang besar untuk mengoperasikan sebuah sistem.

Selain kedua pengaruh diatas, kepercayaan konsumen juga merupakan hal yang dapat berpengaruh dalam hubungan antar manusia (Maia, Lunardi, \& Munhoz, 2017). Trust disebutkan sebagai kesediaan orang untuk setia terhadap sebuah barang atau jasa berdasarkan hal positif yang didapatkan dari barang atau jasa tersebut (Kumar, Adlakaha, \& Mukherjee, 2018).

Kumar et al. (2018) dalam penelitiannya juga mengatakan Trust dalam penelitian lanjutan telah terbukti merupakan penentu penting terhadap penggunaan secara berkelanjutan akan produk atau jasa yang ditawarkan. Kurangnya kepercayaan konsumen dapat berdampak negatif pada keinginan konsumen untuk menggunakan sebuah produk (Curvelo, 2019). 
Ketiga variabel diatas dapat mempengaruhi Intention to Reuse. Hal ini, misalnya dapat diperhatikan dari penelitian sebelumnya yang dilakukan, misalnya, oleh Hatammimi (2015), Intention to Reuse untuk teknologi mengarah pada tujuan akhir konsumen melakukan kegiatan dan dapat dikatakan sebagai alasan dari kepercayaan dan perilaku yang diambil. Didalam penelitian tersebut juga dikatakan penerimaan sebuah teknologi dapat dilihat dari keinginan orang untuk menggunakan teknologi tersebut. Ini berarti dapat disimpulkan bahwa semakin tinggi niat orang untuk menggunakan sebuah teknologi maka semakin tinggi pula tingkat penerimaan orang terhadap teknologi tersebut. Oleh karena itu, kerangka pemikiran penelitian ini sebagai berikut (Gambar 1).

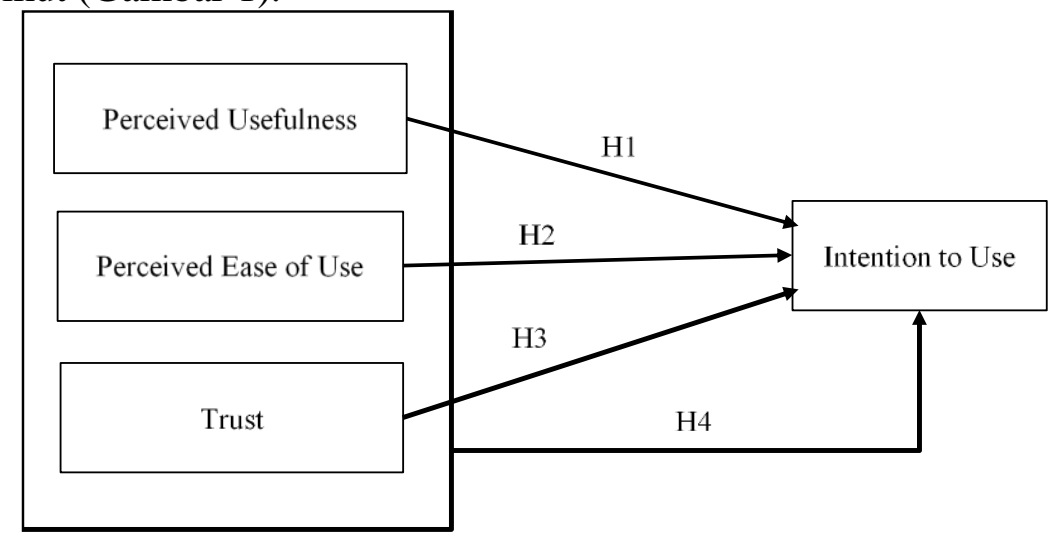

Gambar 1

Kerangka Penelitian

Dari kerangka pemikiran diatas, maka disusun hipotesis dalam penelitian seperti berikut ini :

H1 : Perceived Usefulness berpengaruh signifikan terhadap Intention to Reuse Go-Pay

$\mathrm{H} 2$ : Perceived Ease Of Use berpengaruh signifikan terhadap Intention to Reuse Go-Pay

H3 : Trust berpengaruh signifikan terhadap Intention to Reuse Go-Pay

H4 : Perceived Usefulness, Perceived Ease of Use, dan Trust secara bersamaan berpengaruh signifikan terhadap Intention to Reuse Go-Pay

\section{METODOLOGI PENELITIAN}

Populasi dan Metode Pengambilan Sampel. Jenis penelitian ini adalah deskriptif kuantitatif. Sumber data primer dikumpulkan menggunakan kuesioner yang disebarkan seacara acak kepada 105 responden pengguna Go-Pay di Jakarta, sementara data sekunder dikumpulkan dari beberapa publikasi terkait. Berdasarkan data yang terkumpul, profil mayoritas responden sebanyak $62.9 \%$ berjenis kelamin pria, sebanyak $53,3 \%$ berusia $24-32$ tahun, sebanyak $85.7 \%$ sudah bekerja, sebanyak $55.2 \%$ beraktivitas di daerah Jakarta Barat, sebanyak 51.4\% sudah menggunakan Go-Pay selama 1-2 tahun, dan sebanyak $41 \%$ menggunakan Go-Pay sebanyak 5-15 kali dalam sebulan.

Variabel dan Pengukuran. Variabel dependen dalam penelitian ini yakni Intention to Reuse, sedangkan variabel independennya adalah perceived usefulness, perceived ease of use, dan trust. Pengukuran variabel menggunakan skala Likert 5 poin dimana 1 merupakan "sangat tidak setuju" dan 5 adalah "sangat setuju". Hasil uji validitas dan reliabilitas menunjukkan keseluruhan indicator variabel yang digunakan adalah valid dan reliabel.

Metode Analisa Data. Metode analisis data menggunakan analisa regresi berganda menggunakan software SPSS version 24. Untuk pengujian asumsi klasik yang terdiri dari uji normalitas, uji linearitas, uji heterokedastisitas, dan uji multikolinearitas telah dilakukan dimana hasil menunjukkan semua pengujian telah terpenuhi. 
ANALISA DAN PEMBAHASAN

Hasil uji $\mathrm{F}$ menunjukkan nilai signifikan sebesar 0.000. Ini mengindikasikan bahwa keseluruhan variabel bebas secara bersama-sama berpengaruh terhadap variabel terikat. Nilai signifikansi ini sekaligus pula mengisyaratkan bahwa hipotesis $\mathrm{H} 4$ yang menyatakan ketiga variabel bebas berpengaruh signifikan secara bersama-sama terhadap variabel bebasnya (Tabel $1)$.

Tabel 1

Hasil Uji F ANOVA $^{\mathrm{a}}$

\begin{tabular}{|c|c|c|c|c|c|c|}
\hline \multicolumn{7}{|c|}{ ANOVA $^{\mathrm{a}}$} \\
\hline \multicolumn{2}{|c|}{ Model } & Sum of Squares & $\mathrm{df}$ & Mean Square & $\mathrm{F}$ & Sig. \\
\hline \multirow[t]{3}{*}{1} & Regression & 241.085 & 3 & 80.362 & 17.010 & $.000^{\mathrm{b}}$ \\
\hline & Residual & 477.162 & 101 & 4.724 & & \\
\hline & Total & 718.248 & 104 & & & \\
\hline
\end{tabular}

Untuk uji t, ternyata variabel PU memiliki nilai signifikansi $0.169>0.05$. Ini berarti bahwa variabel PU tidak memiliki pengaruh yang signifikan terhadap variabel ITRU. Hal ini berbeda dengan PEOU yang memiliki nilai signifikansi $0.009<0.05$. Ini menunjukkan bahwa PEOU memiliki pengaruh yang signifikan terhadap variabel ITRU. Demikian pula dengan TR, nilai signifikansinya adalah 0.001 yang lebih kecil dari 0.05. Ini juga berarti bahwa TR memiliki pengaruh yang signifikan terhadap variabel ITRU (Tabel 2).

Tabel 2

Hasil Uji t

\begin{tabular}{|c|c|c|c|c|c|c|}
\hline \multicolumn{7}{|c|}{ Coefficients $^{\mathrm{a}}$} \\
\hline \multirow{2}{*}{\multicolumn{2}{|c|}{ Model }} & Unstandardized & \multirow{2}{*}{$\begin{array}{l}\text { Std. } \\
\text { Error }\end{array}$} & Standardized & \multirow[t]{2}{*}{$\mathrm{t}$} & \multirow[t]{2}{*}{ Sig. } \\
\hline & & & & & & \\
\hline \multirow[t]{4}{*}{1} & (Constant) & 3.358 & 1.707 & & 1.968 & .052 \\
\hline & $\mathrm{X} 1(\mathrm{PU})$ & .110 & .079 & .136 & 1.385 & .169 \\
\hline & $\mathrm{X} 1$ (PEOU) & .218 & .082 & .246 & 2.677 & .009 \\
\hline & X3 (TR) & .266 & .074 & .343 & 3.579 & .001 \\
\hline
\end{tabular}

Hasil uji koefisien determinasi $\left(\mathrm{R}^{2}\right)$ menunjukkan bahwa nilai koefisien determinasi $(\mathrm{R}$ square) yakni sebesar 0.336. Ini mengindikasikan bahwa ketiga variabel PU, PEOU dan TR hanya mampu menjelaskan variabel ITRU sebesar 33.6\% (Tabel 3). Dengan demikian, sebesar $66.4 \%$ sisanya dijelaskan oleh variabel lain yang tidak diteliti. Ini menunjukkan ketiga variabel PU, PEOU, dan TR tidak merupakan variabel penjelas terbaik dalam memberikan pengaruh terhadap ITRU. Oleh karena itu, perlu diteliti lebih lanjut variabel bebas lainnya.

Tabel 3

Hasil Uji Koefisien Determinasi $\left(\mathbf{R}^{2}\right)$

\begin{tabular}{|l|l|l|l|}
\hline \multicolumn{3}{|c|}{ Model Summary $^{\mathrm{b}}$} \\
\hline Model & R Square & Adjusted R Square & Std. Error of the Estimate \\
\hline 1 & .336 & .316 & 2.174 \\
\hline \multicolumn{3}{|l|}{ a. Predictors : (Constant), X1, X2, X3 } \\
b. Dependent Variable : Y1
\end{tabular}

Hasil hipotesis pertama diperoleh bahwa Perceived Usefulness tidak berpengaruh signifikan terhadap Intention to Reuse Go-Pay di Jakarta. Temuan mendukung hasil penelitian Hatammimi (2015) dan Humbani \& Wiese (2019). Variabel Perceived Usefulness tidak mempengaruhi keinginan konsumen untuk menggunakan kembali dompet digital dapat disebabkan masyarakat terutama di Jakarta yang tidak merasa kesulitan walaupun tidak menggunakan dompet digital untuk melakukan pembayaran. Hal ini karena uang tunai yang masih dibutuhkan hampir dalam setiap kegiatan transaksi. Dengan kata lain, masih banyak merchant yang belum menerima pembayaran secara digital. Selain itu juga karena adanya faktor external seperti internet di Indonesia yang sering tidak mendukung sehingga kadang 
tidak memberikan kemudahan dan kecepatan dalam bertransaksi serta banyaknya pesaing yang menawarkan produk sejenis dengan fungsi dan kegunaan yang lebih banyak.

Berbeda dengan temuan diatas, hasil hipotesis kedua diperoleh temuan bahwa Perceived Ease of Use berpengaruh signifikan terhadap Intention to Reuse. Hasil ini mendukung penelitian yang dilakukan Hatammimi (2015). Temuan ini berbeda dengan hasil studi Humbani \& Wiese (2019) yang menemukan Perceived Ease of Use tidak berpengaruh signifikan terhadap Intention to Reuse.

Penjelasan mengapa Perceived Ease of Use berpengaruh signifikan terhadap Intention to Reuse di Jakarta dapat disebabkan karena penggunaan uang tunai sudah dinilai sangatlah mudah dan sederhana. Ini berarti jika muncul dompet digital dengan cara pembayaran yang menyulitkan pengguna, maka pengguna akan lebih memilih untuk tidak menggunakan dompet digital itu.

Untuk Hipotesis ketiga diperoleh hasil bahwa Trust berpengaruh signifikan terhadap Intention to Reuse. Hasil dalam penelitian ini dapat mendukung studi yang dilakukan Ong \& Lin (2015), Kumar et al. (2018), Gong, Liu, Zheng, \& Wu (2018), Maqableh, Masa'deh, Shannak, \& Nahar (2015), Zhu, Lan, \& Chang (2017). Hal ini disebabkan dompet digital berhubungan dengan uang sehingga pengguna membutuhkan kepastian dan perlu mempercayai penyedia jasa bahwa uang dan data pengguna aman.

Saran yang dapat diberikan kepada perusahaan Go-Pay adalah mempertahankan atau mengembangkan proses pengoperasian yang dapat memudahkan pengguna seperi menjaga proses pembayaran agar tetap user friendly, memberikan variasi pilihan bagi pengguna untuk melakukan topup maupun withdraw. Menjaga kepercayaan pengguna juga sangat penting karena sangat mempengaruhi minat pengguna dalam menggunakan Go-Pay. Salah satu caranya adalah menjaga keamanan data pengguna serta membangun citra baik dari brand Go-Pay itu sendiri.

\section{DAFTAR PUSTAKA}

Ajzen, I., \& Fishbein, M. A. (1975). Belief, Attitude, Intention and Behaviour : An Introduction to Theory and Research. Reading, MA : Addison-Wesley.

Bagla, R. K., \& Sancheti, V. (2018). Gaps in Customer Satisfaction with Digital Wallets : Challenge For Sustainability. Journal of Management Development, 37 (6), 442-452.

Curvelo, I. C. (2019). Purchase Intention of Organic Food under The Influence of Attributes, Consumer Trust and Perceived Value. Revista de Gestão, 26 (3), 198-211.

Davis, F. D. (1989). Perceived Usefulness, Perceived Ease of Use, and User Acceptance of Information Technology. MIS Quarterly, 13 (3), 319-340.

Gong, X., Liu, Z., Zheng, X., \& Wu, T. (2018). Why are Experienced Users of WeChat Likely to Continue Using The App? Asia Pacific Journal of Marketing and Logistics, 30 (4), 1013-1039.

Hatammimi, J. (2015). Factors Affecting the Intention to Reuse Mobile Banking Service. International Journal of Research in Business and Social Science, 4 (4).

Humbani, M., \& Wiese, M. (2019). An Integrated Framework for The Adoption and Continuance Intention to Use Mobile Payment Apps. International Journal of Bank Marketing.

Kumar, A., Adlakaha, A., \& Mukherjee, K. (2018). The Effect of Perceived Security and Grievance Redressal on Continuance Intention to Use M-Wallets in A Developing Country. International Journal of Bank Marketing, 36 (7), 1170-1189 .

Maia, C., Lunardi, G., \& Munhoz, A. L. (2017). Factors and Characteristics that Influence Consumers' Participation in Social Commerce. Revista de Gestão, 25 (2), 194-211.

Maqableh, M., Masa'deh, R. M., Shannak, R. O., \& Nahar, K. M. (2015). Perceived Trust and Payment Methods : An Empirical Study of MarkaVIP Company. International Journal of Communications, Network and System Sciences, 8 (11), 409-427. 
Ong, C. S., \& Lin, Y. L. (2015). Security, Risk, and Trust in Individuals' Internet Banking Adoption : An Integrated Model. International Journal of Electronic Commerce Studies, $6(2), 343-356$.

Shidiq, M. J., \& Warnilah, A. I. (2019). Analisis Penerimaan Grup Whatsapp sebagai Media Komunikasi dan Diskusi Guru. Indonesian Journal on Computer and Information Technology, 4 (2), 122-131.

Sikri, A., Dalal, S., Singh, N. P., \& Le, D.-N. (2019). Mapping of E-Wallets with Features. Cyber Security in Parallel and Distributed Computing, 245 - 262.

Singh, N., Srivastava, S., \& Sinha, N. (2017). Consumer Preference and Satisfaction Of MWallets : A Study on North Indian Consumers. International Journal of Bank Marketing, 35 (6), 944-965.

Zhu, D. H., Lan, L. Y., \& Chang, Y. P. (2017). Understanding the Intention to Continue Use of a Mobile Payment Provider: An Examination of Alipay Wallet in China. International Journal of Business and Information, 12 (4), 369-390.

https://finance.detik.com/moneter/d-4398523/hasil-survei-go-pay-jadi-uang-elektronikpaling-banyak-dipakai-di-ri 